\title{
Load shift potential of electric vehicles in Europe
}

\author{
Sonja Babrowski ${ }^{\mathrm{a}, *}$, Heidi Heinrichs ${ }^{\mathrm{b}}$, Patrick Jochem ${ }^{\mathrm{a}}$, Wolf Fichtner ${ }^{\mathrm{a}}$ \\ a Institute for Industrial Production (IIP), Chair of Energy Economics, Karlsruhe Institute of Technology (KIT), Hertzstraße 16, Building 06.33, \\ 76187 Karlsruhe, Germany \\ ${ }^{\mathrm{b}}$ Institute of Energy and Climate Research (IEK), System Analysis and Technology Evaluation (IEK-STE), Forschungszentrum Jülich, Wilhelm-Johnen-Straße, \\ 52425 Jülich, Germany
}

\section{H I G H L I G H T S}

- Examination of six European mobility studies to display load shift potential.

- Country specific charging load curves of electric vehicles.

- Possibility to charge at the work place significant for load shift potential.

- At least $45 \%$ vehicle availability at home or at the work place during the day.

- Big potential for load shifting through controlled charging.

Keywords:

Load shift potential

Electric mobility

Load profiles

Energy system modeling

\begin{abstract}
A B S T R A C T
Many governments highly encourage electric mobility today, aiming at a high market penetration. This development would bring forth an impact on the energy system, which strongly depends on the driving and charging behavior of the users. While an uncontrolled immediate charging might strain the local grid and/or higher peak loads, there are benefits to be gained by a controlled charging. We examine six European mobility studies in order to display the effects of controlled and uncontrolled unidirectional charging. Taking into account country specific driving patterns, we generate for each country a charging load curve corresponding to uncontrolled charging and consider the corresponding parking time at charging facilities in order to identify load shift potentials. The main results are that besides the charging power of the vehicles, the possibility to charge at the work place has a significant influence on the uncontrolled charging curve. Neither national nor regional differences are as significant. When charging is only possible at home, the vehicle availability at charging facilities during the day for all countries is at least $24 \%$. With the additional possibility to charge at work, at least $45 \%$ are constantly available. Accordingly, we identified a big potential for load shifting through controlled charging.
\end{abstract}

\section{Introduction}

In the last five years, electric vehicle (EV) registrations have increased significantly in most industrialized countries [1]. Until now, hybrid electric vehicles which have a conventional engine loading the battery hold the highest share of the EV fleet. As they do not connect directly to the grid, there is no effect on the electricity industry yet. However, this might change in the future. Whereas the number of registered battery electric vehicles (BEV) is still limited to a few hundreds and plug in electric vehicles (PHEV) were non existent until recently; their registration has increased strongly in the past two years [1].

\footnotetext{
* Corresponding author. Tel.: +49721608 44676; fax: +49721608 44682 . E-mail address: Sonja.babrowski@kit.edu (S. Babrowski).
}

From the point of view of the electricity industry, the relevant difference regarding vehicles featuring a plug is their additional electricity consumption. A raise in electricity consumption due to a growing share of EVs might lead to additional challenges in the future electricity system. However, already today we face some outstanding challenges in the electricity system with more volatile, less controllable and at the same time more decentralized elec tricity generation. This is mainly due to the increasing electricity generation by wind and photovoltaic systems, which is driven by the political objective to reduce greenhouse gas emissions (e.g., Erdmenger et al. [2]).

The additional electricity demand by EVs has two main impacts: (1) the additional generation of electricity by power plants and (2) an additional load on lower grid levels. Although this is going to change in the future, in the coming years the first impact will be more or less negligible because of the marginal share of additional 
electricity [3]. As the EV fleet continues to grow, new electricity generation units might have to be commissioned especially to satisfy the additional demand. The additional load on lower grid levels might additionally lead to grid problems in terms of voltage deviation, power congestion, and power losses [4-6]. This holds especially true for certain points in time and grid topologies. Several technical measures could help to avoid these incidents. Kempton and Tomić [7] therefore introduced modified EV charging processes: (1) controlled unidirectional charging and (2) controlled bidirectional charging (or vehicle to grid, V2G). These techniques can be assigned to demand response measures, which try to reverse the previously unchanged principle that electricity demands are more or less price inelastic and that electricity supplies have to be adjusted accordingly. As electricity generation from volatile re newables cannot be synchronized with the demand at all times anymore, there is a growing need for balancing measures such as power plants for peak load, storage systems or demand response measures $[8,9]$. Demand response measures could be used to fill valleys in the demand and thus help to improve the cost effec tiveness of base load capacities by raising their full load hours. Since private households have a low price elasticity, their load shift po tential (LSP) is low [10]. EVs will, however, increase these potentials due to their high share in the overall household electricity demand and their high temporal charging flexibility $[3,11]$. This LSP can support balancing electricity demand and generation.

It has to be noted that the use of the LSP by EVs in order to facilitate the integration of renewables or to raise the full load hours of conventional generation units is in reality subject to many restrictions [12]. Besides the restrictions of the lower grid level there are further technical parameters that have to be kept in mind for a holistic analysis of the implications of load shifting. For example, the battery longevity depends on the charging patterns and thus might restrict the economical LSP [13]. Consideration of the conflict between charging time and charging losses also leads to a different use of the LSP [14].

A matter of principal importance is the user acceptance of such demand measures [15]. Some kind of user interaction is going to be needed to exploit the full LSP. Different price signals can serve as incentives for the users and lead to different charging patterns [16]. However, price signals have to be coordinated and locally distin guished [17]. Otherwise, all EV users charge at the same time when prices are low and new load peaks occur.

Considering a specific national background, the positive effect that applying demand response measures to EVs can have on the energy system has been examined by several authors as for example in Lund and Kempton [8] with a focus on the Danish en ergy system or in Fernandes et al. [18] in the context of the Spanish power system. Weiller [19] based her analyses on US mobility data while Dallinger et al. [20] examined how EVs could be integrated into the German reserve market based on a dynamic simulation of the German mobility behavior. However, none of these studies looked at national or regional differences in mobility behavior and the corresponding effects on EV charging patterns.

In order to make a first estimate of how additional loads caused by EVs could influence the national, as well as the European energy system, we analyze a) how an uncontrolled charging would change the overall load and b) the potential benefits of load shifting through postponing the EV charging processes.

To analyze the situation where EVs are charged in an uncon trolled way as soon as possible and with the maximum power available, EV load curves have to be extracted from mobility studies. After identifying six European mobility studies suitable for such extraction, we develop an algorithm that takes scenario specific conditions into account and creates an EV load curve by inter preting trip data. Through examination of different scenarios and comparison of different national and regional load curves, the main influencing parameters on the uncontrolled load curve are identi fied. To examine the potential benefits of load shifting, the whole energy system must be considered at the same time. Therefore, we derive limits to the LSP from the mobility data that can be inte grated into energy system models. While the lower limit is based on a share of EVs that are charged in an uncontrolled way, the upper limit is derived from the EV availability at charging facilities (also called Electric Vehicle Supply Equipments (EVSEs)). To further assess the use of those limits, we implemented them in the existing energy system model PERSEUS EMO [16].

The structure of the paper is as follows: In the section below (Section 2) we introduce our methodology of extracting the EV load curves. Next (Section 3.1), we analyze the influence of different parameters on the load curves based on a pessimistic, a reference and an optimistic scenario. Section 3.2 presents the different load curves for the European member states and Section 3.3 focuses on the load curves of different residential areas in Germany. Section 4 shows an example of possible challenges in the overall load for some German regions, with a prediction of high $\mathrm{EV}$ penetration and a high photovoltaic (PV) generation. Section 5 focuses on the boundaries of the LSP by EVs and Section 6 gives an example of the integration of the LSP in an energy system model. Section 7 con cludes with a short summary and a discussion of the main results.

\section{Methodology of EV load curve extraction}

In order to analyze the influence of country specific driving behavior on charging load curves, we evaluate the data of six Eu ropean mobility studies. For further countries, current mobility studies did not exist or studies did not contain the necessary data. For other studies, again no access to the original data is granted. Table 1 shows the considered countries and the corresponding studies. Further details about the availability of European mobility studies and the process of identifying the studies mentioned here are presented in Heinrichs [21].

The data of the mobility studies has been used to generate the national EV load curves. Therefore, we have used data about trips made by drivers/vehicles suitable for electric mobility. Hence, in a first step, we have checked for each driver/vehicle their respective technical and economic suitability for electric mobility. Technical constraints consists e.g., in parking availability, the relation regarding persons and vehicles per household and an upper limit to the total driven mileage on the reported day. Furthermore, since the investment in an EV is higher than in a conventional car but variable costs per kilometer are significantly lower [22], a lower limit to the yearly driven mileage is required as an economic constraint. For more details on how we have identified suitable

Table 1

Considered European studies [21]

\begin{tabular}{|c|c|c|c|}
\hline Country & Study & Published by & Year \\
\hline Germany & $\begin{array}{l}\text { Mobilität in } \\
\text { Deutschland }\end{array}$ & Infas, DLR & 2008 \\
\hline Denmark & $\begin{array}{l}\text { The Danish national } \\
\text { travel Survey }\end{array}$ & $\begin{array}{l}\text { DTU transport } \\
\text { Institut für Transport }\end{array}$ & 20062009 \\
\hline Finland & & $\begin{array}{l}\text { Väestötietojärjestelmä } \\
\text { Population Register Centre }\end{array}$ & $2004 / 2005$ \\
\hline Netherlands & $\begin{array}{l}\text { Mobiliteitsonderzoek } \\
\text { Nederland } 2008\end{array}$ & $\begin{array}{l}\text { Rijkswaterstaat Ministerie } \\
\text { van Verkeer en Waterstaat }\end{array}$ & 2008 \\
\hline Switzerland & $\begin{array}{l}\text { Mobilität in der } \\
\text { Schweiz }\end{array}$ & $\begin{array}{l}\text { Schweizer Eidgenossenschaft; } \\
\text { Bundesamt für Statistik BFS }\end{array}$ & $2005 / 2006$ \\
\hline $\begin{array}{l}\text { United } \\
\text { Kingdom }\end{array}$ & NTS database & $\begin{array}{l}\text { National Centre for Social } \\
\text { Research }\end{array}$ & 2006 \\
\hline
\end{tabular}


users for the purpose of analysis within this paper we refer to $[21,23,24]$.

Having identified the drivers/vehicles suitable for electric mobility, we use the data of trips made by them to extract the EV load curves. In this context, a trip is defined as a single way in one direction. A tour to the grocery store and back would consist of two trips. A trip chain, on the other hand, consists of all trips until the next charging opportunity is reached. The extracted charging curve mirrors an uncontrolled instantaneous charging - charging as much and as soon as possible.

To generate this charging curve, an algorithm has been devel oped and implemented in Microsoft ${ }^{\circledR}$ Excel (cf. Fig. 1). At first, the electricity needed ("load to be charged") for each trip is calculated by multiplying the distance of each trip with the scenario specific consumption. Additionally, it has to be decided whether charging after each trip is possible or not. In this context, charging at home is always allowed, whereas the opportunity to charge at work or at public spots depends on the considered scenario. Additionally, charging after the last trip of the day is always allowed, no matter where the EV is parked then. When there is no charging oppor tunity and it is not the last trip of the day, the load needed for the considered trip is added to the load of the next trip. For each stop with a charging opportunity, the parking duration is calculated by looking at the end time of the trip and the starting time of the following trip. As most mobility surveys only refer to one reporting day, the parking time after the last trip of the day is derived from the end time of that trip and the starting time of the first trip of the considered day. The trips and the electricity needed for them are considered chronologically. With this electricity demand and the scenario dependent average charging power, we calculate the time needed for charging after a trip chain. When charging the electricity needed for the trip chain would take longer than the available parking time at the considered charging opportunity, the residual electricity that cannot be charged is transferred to the next charging opportunity. For each charging opportunity, the starting time of each charging transaction is determined by the end time of the trip before. In order to avoid charging too much because of the rounding to hourly periods, only the amount left is charged in the last hour of the charging transaction. Considering a situation of an uncontrolled charging with a maximum charging power of $6 \mathrm{~kW}$ and an electricity de mand of $8 \mathrm{kWh}$, this would, for example, mean that in the first charging hour, $6 \mathrm{kWh}$ are charged and in the second hour only the remaining $2 \mathrm{kWh}$ with an average power of $2 \mathrm{~kW}$.

Through the described approach it could be determined for each driver or vehicle in the mobility data bases when and how much is charged. Summarizing the load charged at each hour of the week overall drivers/vehicles considered, the EV load curves could be extracted.

Since according to Gringmuth [25], mobility schedules are similar for working days and weekend days, we simplified the load curves considering one curve for Monday to Friday and a second for the weekend. Furthermore, the corresponding load curves were converted to represent the shares of the whole day load. Thus, the hourly values of the weekend and the working day curves sum up to one. Hence, it is possible to multiply the curves with the day load of any considered number of EVs in order to generate absolute hourly values.

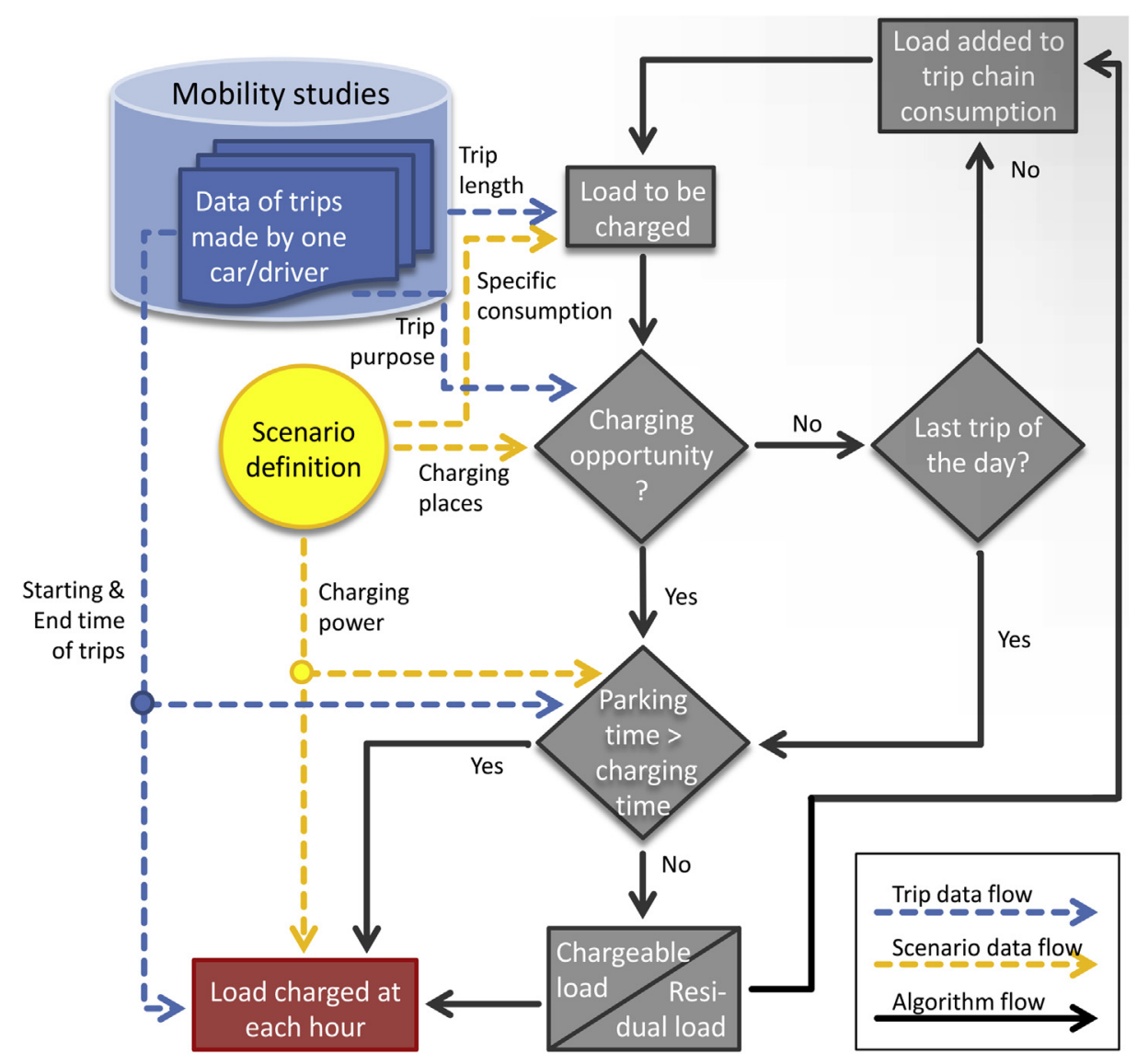

Fig. 1. Schematic illustration of the algorithm developed to extract the EV load curves. 
Table 2

Overview of the scenario parameters.

\begin{tabular}{|c|c|c|c|c|}
\hline Scenario & & $\begin{array}{l}\text { Pessimistic } \\
\text { scenario }\end{array}$ & $\begin{array}{l}\text { Reference } \\
\text { scenario }\end{array}$ & $\begin{array}{l}\text { Optimistic } \\
\text { scenario }\end{array}$ \\
\hline $\begin{array}{l}\text { Place of } \\
\text { charging }\end{array}$ & [ ] & At home & $\begin{array}{l}\text { At home \& } \\
\text { At work }\end{array}$ & $\begin{array}{l}\text { At home \& } \\
\text { At work \& } \\
\text { Shopping etc. }\end{array}$ \\
\hline \multirow[t]{2}{*}{$\begin{array}{l}\text { Power of } \\
\text { charging }\end{array}$} & {$[\mathrm{kW}]$} & $100 \%$ with 3.5 & $\begin{array}{l}60 \% \text { with } 3.5 \\
40 \% \text { with } 10.5\end{array}$ & $\begin{array}{l}40 \% \text { with } 3.5 \\
40 \% \text { with } 10.5 \\
20 \% \text { with } 60\end{array}$ \\
\hline & & $\begin{array}{r}3.5 \text { on } \\
\text { average }\end{array}$ & $\begin{array}{r}6.3 \text { on } \\
\text { average }\end{array}$ & $\begin{array}{l}17.6 \text { on } \\
\text { average }\end{array}$ \\
\hline Consumption & {$[\mathrm{kWh} / 100 \mathrm{~km}]$} & 21.6 & 19.6 & 17.7 \\
\hline Mode & IEC 61851 & 1 or 2 & 1 to 3 & 1 to 4 \\
\hline
\end{tabular}

\section{Charging load curves}

\subsection{Different scenarios}

For identification of crucial parameters of the charging load curves, three different scenarios where considered. As shown by Weiller [19] the allocation and power of EVSEs have a significant influence on the EV load curves. Hence, the following scenarios differ mainly in terms of the charging power and the allocation of (public) EVSEs. Besides, technological parameters such as the electricity consumption per $\mathrm{km}$ also differ between the scenarios. The battery size is about $30 \mathrm{kWh}$ for all three scenarios. To cover a wide range of possible future developments, one optimistic, one pessimistic and one - from our perspective - rather realistic reference scenario are compared, forming a "scenario trumpet".

The charging process of EVs is conceivable for allocations such as at home, at the work place or at public places such as, for example, the curb of a street or the parking lot of a supermarket. The most important place to charge will be at home [26,27]. Here, the vehicle could be either charged by the domestic socket outlet (so called mode 1 or 2 charging) or through a wall box with a mode 3 plug. This "mode" nomenclature is defined by IEC61851 1 . Mode 3 charging is characterized by additional protection measures i.e., a standardized communication between the charging infrastructure and the EV to ensure that power is only delivered when a vehicle is connected to the socket outlet, the plug is correctly inserted, and the earth circuit is proved to be sound [28]. Whereas with modes 1 and 2 , controlled charging is limited to setting the starting time of the charging process through an extra timer, the communication interface of mode 3 allows an advanced controlled charging. This advanced control takes into consideration the state of charge (SoC) of the battery and further limitations by the battery management system of the vehicle. Price signals can also be considered. Even though a fast charging by mode 3 is possible, it is limited to $250 \mathrm{~A}$.
Charging by DC current (mode 4) allows much higher charging rates.

In the pessimistic scenario, it is assumed that charging takes only place at home by means of a domestic plug (mode 1 or 2 ). The charging power is limited to the usual European household socket power of $3.5 \mathrm{~kW}$. For the reference scenario, only $60 \%$ of the charging transactions are accomplished at home by $3.5 \mathrm{~kW}$ and another $40 \%$ by $10.5 \mathrm{~kW}$ (mode 3 ) either at home or at work. In the optimistic scenario, additionally the possibility of fast charging with at least $60 \mathrm{~kW}$ (mode 3 or mode 4 ) is specified to be at $20 \%$. Those EVSEs allow controlled charging and may be available at work places, shopping centers, etc. Another $40 \%$ are considered to charge by $10.5 \mathrm{~kW}$ (mode 3 ), and only $40 \%$ are assumed to charge at home with $3.5 \mathrm{~kW}$ (mode 1 or 2). Table 2 shows the different parameters.

In the following, the resulting scenario charging load curves are displayed for the example of Germany. Looking at the uncontrolled charging on a working day in Germany (s. Fig. 2), the considerable difference between the curve of the pessimistic scenario and the curve of the other two scenarios becomes visible. The missing peak in the morning is due to loading being restricted to the home and being not possible at the work place. The strong influence of the possible charging places on the charging curve is in line with the findings by Weiller [19]. Another difference is due to the minor power of charging, which results in a lower, but longer lasting evening peak. This effect is also visible comparing the evening peak of the reference and the optimistic scenario.

In Fig. 2, the share of the daily load consumed through driving in the considered hour is also displayed. The peaks of driving con sumption lie in the morning at around 7 a.m. and in the evening at around 5 p.m. Obviously and not surprisingly, commuting is the main driver for daily traffic volume patterns. It can be seen that the charging peaks of the uncontrolled charging strategy occur at a later stage than peak consumption as people start charging when they arrive and charge for some time. People arriving at 7 a.m. might still charge at 8 a.m. simultaneously with those arriving at 8 a.m., which results in a charging peak at 8 a.m. even though most people actually have already arrived at home an hour earlier. The trips at the weekend are more evenly spread and the difference due to the possibility to charge at work is smaller.

\subsection{National differences}

In the following, the resulting charging load curves for the considered countries are only displayed for the reference scenario. Assuming a high share of EVs, differences in national driving patterns would clearly lead to different charging load curves. However, in the considered reference scenario, where charging at work is possible, all national charging load curves show a similar pattern: a major peak in
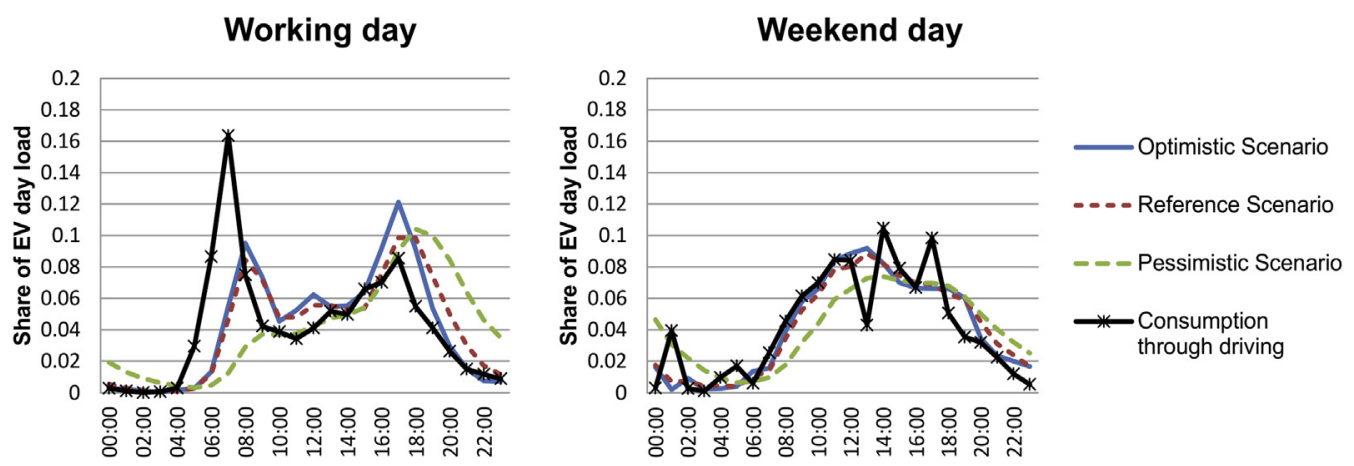

Fig. 2. Scenario-specific charging curves for Germany on a working day (left) and a weekend day (right). 

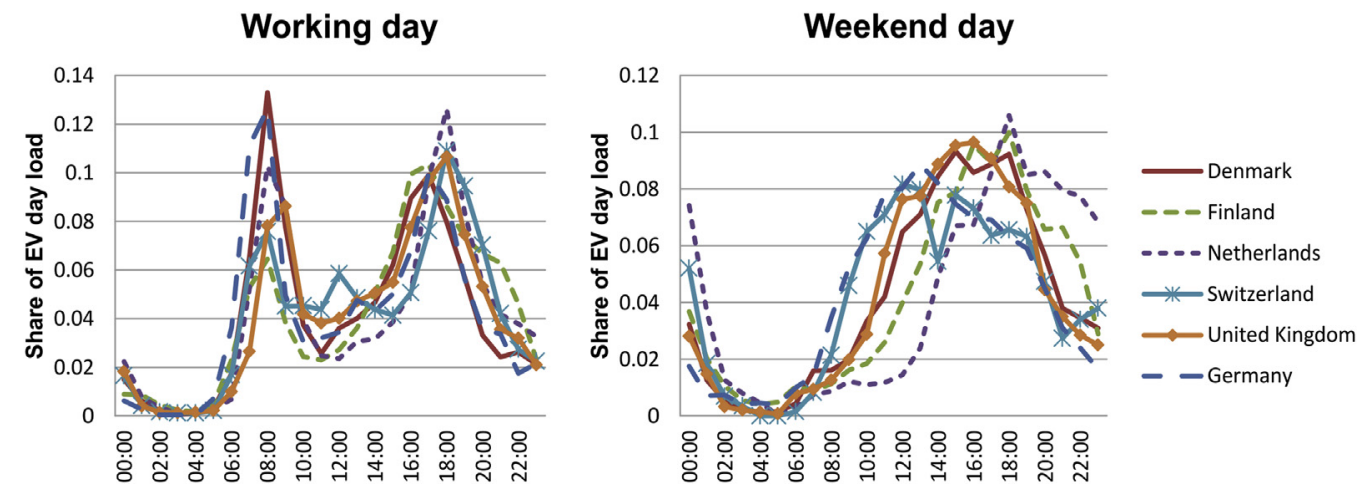

Fig. 3. Country-specific charging load curves on a working day (left) and on a weekend day (right).

the morning after driving to work in the case of the uncontrolled charging load curve (cf. Fig. 3). A second peak occurs in the evening hours when people return home. Differences appear mainly in the amplitude. For Germany and Denmark, the morning peak is higher than the evening peak. An explanation could be that people start their day more simultaneously compared to the other four countries (at around 7 a.m.). Also, their return back home in the evening (at around 5 p.m.) shows a wider distribution (maybe due to making detours for shopping, leisure, departing earlier/later from work, etc.). For the other countries, the evening peak is higher. Hence, in these countries the return in the evening is more homogenous than the departures in the morning. The Finnish people seem to be even more flexible in time as amplitudes are lower and wider.

The charging load curves also imply other national differences such as that the Germans seem to be a little earlier at the working place and are therefore able to start charging at the work place sooner. In comparison to the others, the Swiss seem to drive rela tively large distances at lunch time, and the Dutch and Finnish people seem to leave work about an hour earlier.

For the weekends, charging curves are significantly more het erogeneous. One reason for this could be the few datasets repre senting the weekends. People seem to leave their homes between 8 and 9 a.m. and return in the afternoon between 2 and 7 p.m.

\subsection{Regional differences in Germany}

In order to examine the influence of different regional condi tions, the German data set was further divided into four different types of residential areas. Fig. 4 shows the categorization and the distribution of the BBSR residential areas in Germany [29].

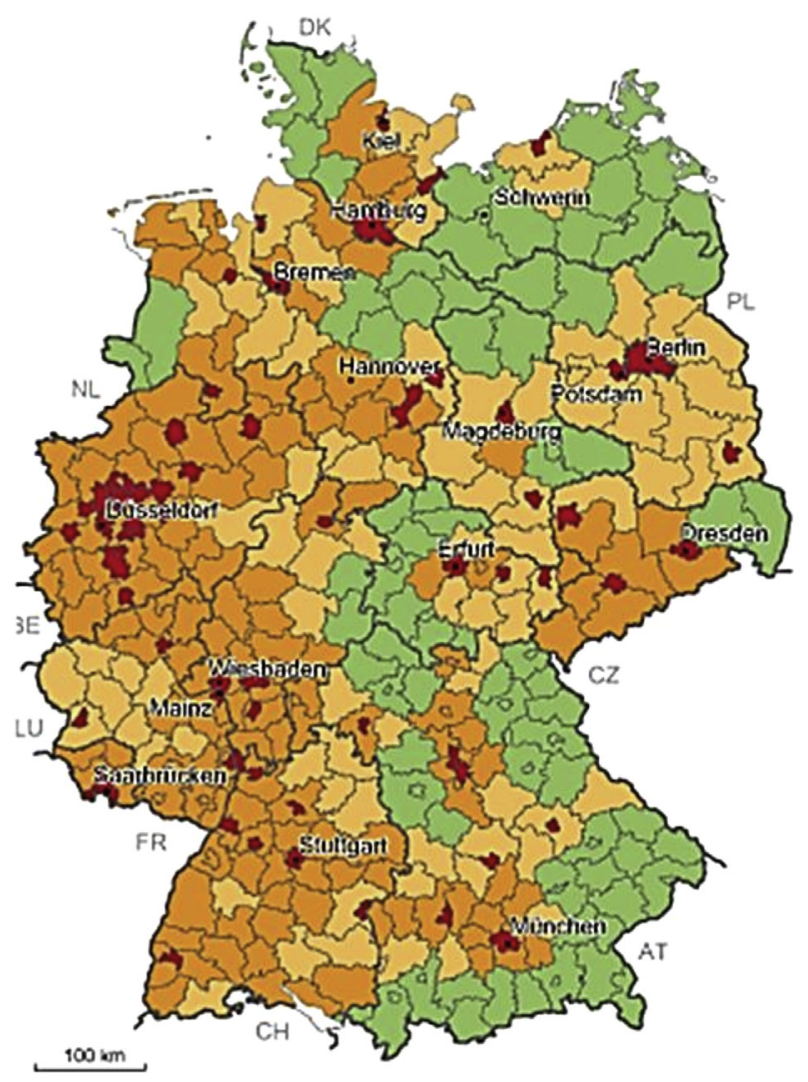

Nucleated town

Largly urban

Largly rual

Ruel Area

Fig. 4. Residential areas in Germany (based on [29]). 
In the following, differences in charging load curves for a working day due to residential area types in Germany are analyzed based on the reference scenario (cf. Fig. 5). For an examination of those differences on a weekend day there was too little data. Compared to the other area types, the largely rural area type seems to charge more in the evening and less in the morning on a working day. This could be an indicator of long ways for shopping or leisure activities where the vehicle cannot be charged. For the nucleated towns, the morning peak seems to be stronger than elsewhere. This might indicate that inhabitants of the city centers drive compara tively little in the afternoons or evenings i.e., only drive to and from work by car while other activities are reached by foot or public transport. The differences in the charging load by residential areas may be relevant for the additional stress on the corresponding distribution networks.

The unique and historically grown distribution networks significantly differ with respect to their load carrying capacities, which make a universally valid estimate of the potential impact of any EV penetration rate impossible [5]. This is especially true for national comparisons, and even for Germany alone, distribution networks differ strongly in their topology, technology and current load in different residential area types and thus differ in their ca pacity to integrate EVs $[5,30]$. As stated in Pollok et al. [5], the transformer power per household tends to be lower in residential areas with a high population density and cables tend to be shorter. This leads to a different vulnerability of a transformer or cable overload through electric mobility $[5,30]$. Another reason besides the net topology for a separate consideration of residential area types is the prediction that most of the EV users are expected to be living in largely urban or rural areas [22].

Thus, the situation in residential areas differs in terms of net topology, EV penetration rate, and charging curve. This makes the distinction between residential area types valuable for the exami nation of impacts of electric mobility.

\section{Relation of EV load to existing load}

In order to make a first estimate of potential benefits of EV load shifting, the existing "conventional load" caused by households and industry has to be considered. Also important for possible benefits of load shifting is the inflexible electricity generation in terms of base load capacities or volatile renewable energy. Therefore, we give two extreme examples of how load shifting could be useful for a) increasing the base load and b) integration of PV electricity.

The progression of the average national load curves of a summer working day as of today can be seen in Fig. 6. Since there are no significant national differences, neither in the EV charging curves nor in the conventional load curves, only Germany is represented as an example in the following.

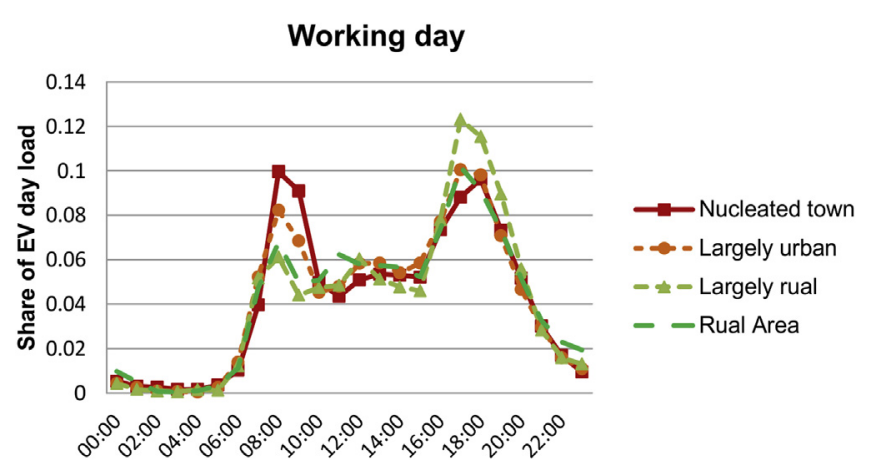

Fig. 5. Residential area-specific charging load curves on a working day.

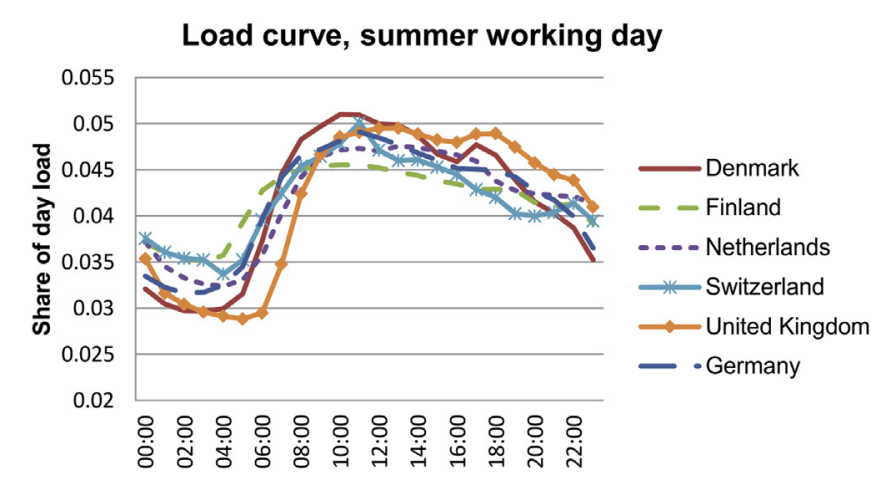

Fig. 6. Country-specific load curves in summer on a working day.

In order to analyze an absolute worst case scenario, we have made a quality analysis of the possible influence of EVs on the German energy system. Therefore, we assume that $100 \%$ of the mileage by car is replaced by BEVs. Today, in Germany there are about 43 million passenger cars which on the average drive about $12,000 \mathrm{~km}$ per year [31]. With a specific consumption of $19.6 \mathrm{kWh} /$ $100 \mathrm{~km}$ according to the reference scenario, an additional elec tricity demand of about 101 TWh per year arises. For 2011, this would have meant an increase in the electricity demand in Ger many of about $20 \%$ to 645 TWh. However, due to the current changes in the electricity generating system and the underlying BEV charging patterns this does not necessarily mean that the amount of installed capacity has to increase by $20 \%$, too. Instead, there is a chance to facilitate the current imposition in the energy sector due to an increase in flexibility in terms of demand response $[8,32,33]$. The gained flexibility in load could either be transferred to times with a high renewable feed in in order to facilitate their integration or to times with a low demand in order to increase the minimum demand ("valley filling") [18]. This would make it possible for base load units to increase profitability by operating at full capacity for more hours and thus at their best efficiency.

Assuming an equal use on working days and weekends, the 101 TWh additional load per year would mean that on average, $281 \mathrm{GWh}$ would be consumed by EVs per day. Taking into account the average load curve of a summer working day in 2011 [34], the uncontrolled charging strategy will change the overall load as shown in Fig. 7.

According to the ENTSO E data, the lowest load levels of the "conventional load" occur during the night time from midnight to 6 a.m. Those low loads determining the "base load" would not be changed by uncontrolled EV charging (cf. Fig. 7). Instead, the peak

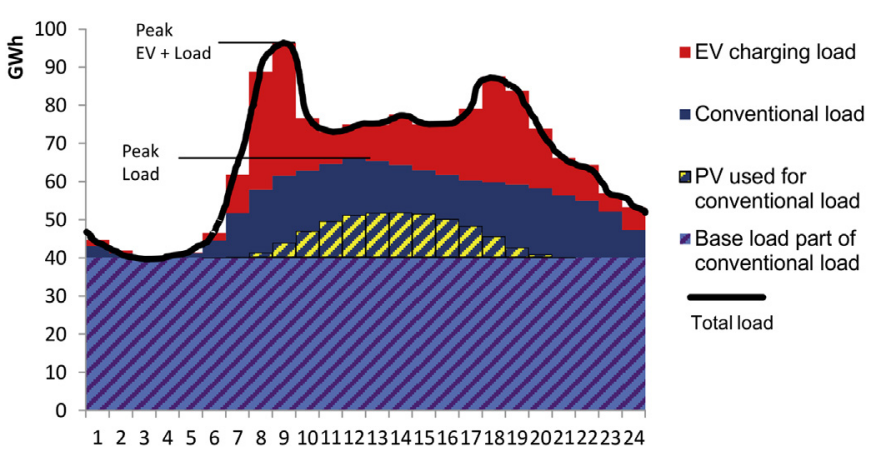

Fig. 7. Conventional load and additional load for EVs on a working day without load shifting. 


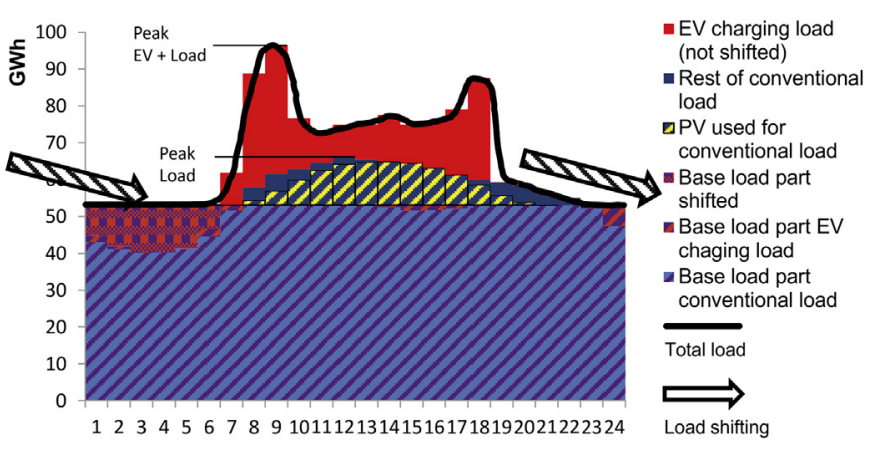

Fig. 8. Increase in the base load through EV load shifting.

load during the day would rise and new higher peaks would occur in the morning at around 9 a.m. after people arrive at the work place and at around 6 p.m. when they arrive at home. With the possibility of a controlled charging, the resulting peaks could be essentially reduced. Another potential benefit of load shifting could be to increase the base load. Through, for example, shifting the load from EVs arriving at home after 6 p.m. to the night hours, the base load could be increased by about $25 \%$ (cf. Fig. 8). Neglecting possible peaks in wind feed in during the night, this would help to increase the full load hours of thermal generation units and thus increase their efficiency and cost effectiveness.

While the average electricity generation by PV in 2011 in Germany was low compared with the overall load [35] (cf. Fig. 7), the situation could be different for some grid sections in the southern part of Germany, where the solar radiation is higher. Considering the target of the German government to increase the share of renewable electricity generation to $80 \%$ until 2050 [36], the share of PV generation could rise drastically in the future. For this situation, EVs could facilitate the integration of PV electricity. By way of example, we examine a day in which the PV feed in of the considered summer day in 2011 is multiplied by five. When the EVs are charged uncontrolled, only about one third of the EV electricity can be charged directly by PV feed in (cf. Fig. 9). However, taking into account that most cars are not used while their owners work and that the morning peak comes from people driving to work, there is the potential to shift the EV electricity that is charged at work places towards the midday hours via controlled charging. Through a shift of up to $6 \mathrm{~h}$, the share of EV electricity that could be charged by PV can be raised to about a half (cf. Fig. 9). Through this shift, all surplus electricity through PV could be integrated. In the case of distributed PV generation or even better a PV system close to the EVSEs at the work place, another benefit would be that neither the EV load nor the PV feed in would burden the local grid.

\section{EV load shift potential}

As stated above, an upper and lower bound must be found to be able to estimate the general LSP of EVs. As an upper limit to the charging load we consider the amount of EVs available at EVSEs. Based on the mobility studies, we extract this data considering the starting time of parking at an EVSE and its duration. The sum of parked vehicles at a certain hour is then divided by the total number of vehicles considered on a working respectively weekend day. In order to obtain the absolute upper limit, this share of EVs parked at an EVSE has to be multiplied with the total amount of considered EVs and the average charging power corresponding to the considered scenario. For the pessimistic scenario, this criterion is the most restrictive since no charging at the working place is possible (cf. Fig. 10). While the possibility to charge at work has a tremendous effect on the share of EVs available, the possibility to charge while shopping or visiting friends leads to only minor dif ferences between the reference and the optimistic scenario.

When charging is only allowed at home (pessimistic scenario), there would always be at least $41 \%$ of the vehicles available at EVSEs in Germany (cf. Fig. 10). On the weekend, as many as 70\% are always available. For other countries, the minimum availability is not quite as high when charging is only allowed at home, the lowest for the Netherlands on a working day at 12 o'clock with $24 \%$. For the reference scenario, however, when charging is allowed at home and at work considering all countries, at least $45 \%$ of the vehicles are always available for load shifting, on working days even $68 \%$ (cf. Fig. 11). After midnight until about 5 o'clock, almost all vehicles (over 99\%) are parked at home and thus available for load shifting.

The lower limit of the LSP is nontrivial. In reality people are not going to plug in their EVs whenever they have the possibility to do so. It is not even said that they charge each day the amount of electricity that they are going to use that day. People with low daily distances could only charge every other day or even less. However, having no lower limit at all respectively of zero would mean that nobody would implicitly want their EVs to be charged at daytime and that the EV day load could be shifted completely to the night time. This is not realistic for people with a daily traveling distance higher than the possible EV range (with one battery charge). Therefore, we consider the limit given by the uncontrolled charging as binding for drivers traveling more than the range of today's EVs of about $100 \mathrm{~km}$ per day. According to the German mobility survey [31], only about $10 \%$ of the drivers have daily distances above $100 \mathrm{~km}$. This means that we assume that a share of $10 \%$ of the total EV day load is charged according to the uncontrolled charging curve and that $90 \%$ of the EV day load can be shifted only being restricted by the upper limit throughout the day.

Taking into account the future development of the batteries that might lead to an extension of the vehicle range, the lower limit
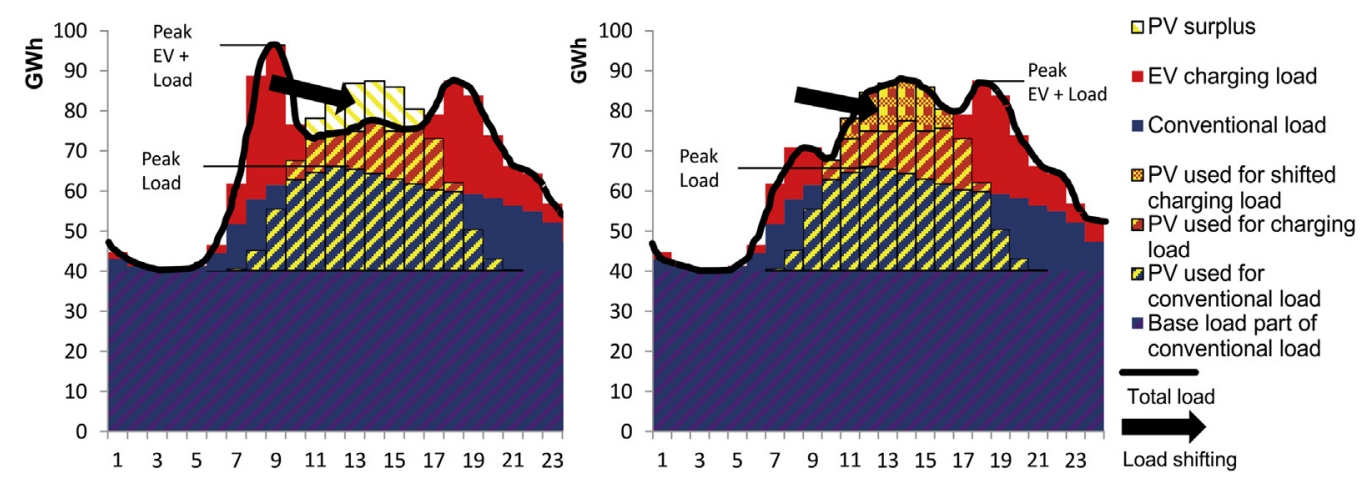

Fig. 9. Integration of PV generation through load shifting; uncontrolled charging (left), charging with load shifting (right). 

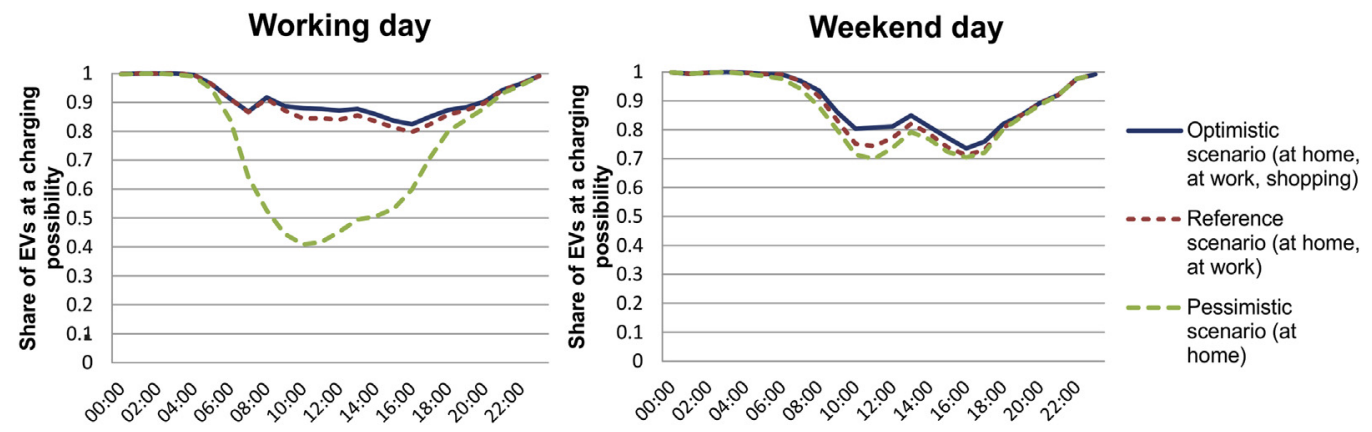

Fig. 10. Availability of EVs at EVSEs in Germany according to scenarios on a working day (left) and on a weekend day (right).
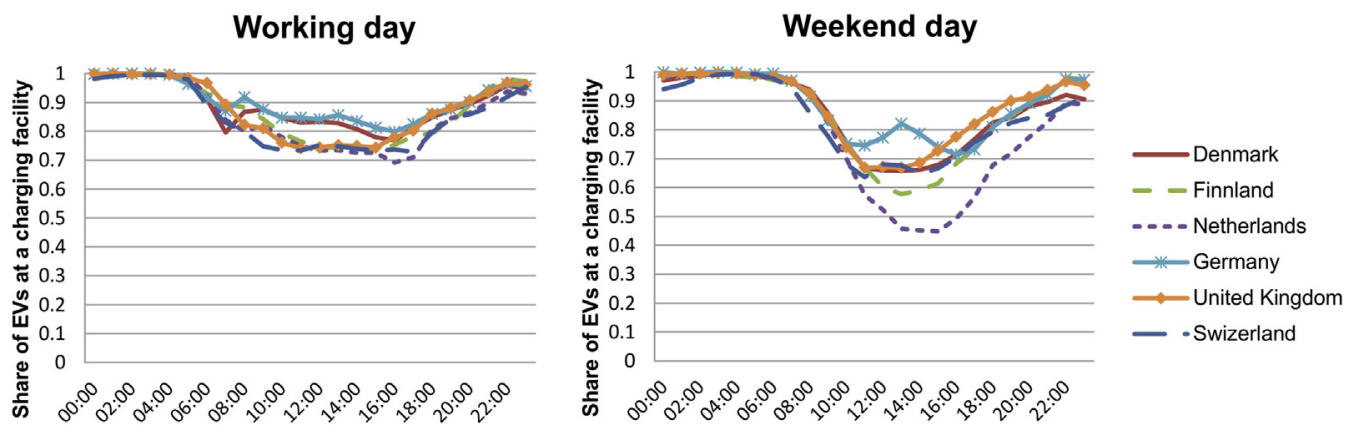

Fig. 11. Availability of EVs at EVSEs according to the reference scenario on a working day (left) and on a weekend day (right).

would become less restrictive. With a range of $150 \mathrm{~km}$, for example, only $5 \%$ of the drivers would be forced to charge during the day [31]. Nevertheless, we stick to the $10 \%$ of the daily electricity demand by EVs to be bound by the uncontrolled charging curve in order to consider unplanned charging processes and to include a kind of "safety margin". Obviously, this lower limit is anyway far from reality according to concerns of vehicle users (cf. Franke et al. [37]).

In the following, we assume again that all of the 43 million vehicles in Germany are replaced by BEVs, needing 278 GWh per day in the reference scenario. Because of the differences in the vehicle efficiency in the pessimistic scenario, $310 \mathrm{GWh}$ would be needed and in the optimistic scenario $254 \mathrm{kWh}$. This load multi plied with the lower limit corresponding to $10 \%$ uncontrolled charging results in the absolute lower limits shown in Fig. 12. For the reference scenario, the value for the upper limit is the product of 43 million vehicles times the average charging power of $6.3 \mathrm{kWh}$, which equals $271 \mathrm{GW}$, times the EV charging availability. For the pessimistic scenario, the 43 million vehicles times $3.5 \mathrm{~kW}$ equal $151 \mathrm{GW}$ which together with the EV charging availability forms the upper limit to the amount charged each hour. The upper limit for the optimistic scenario depends also on the day load instead of the maximum charging power since the energy amount charged with maximum power within $1 \mathrm{~h}$ with $929 \mathrm{GWh}$ would be higher than the needed day load of $254 \mathrm{GWh}$. However, if only $50 \%$ of the ve hicles park near an EVSE, maximally $50 \%$ of the EV day load can be charged within that hour independently from the maximal charging power.

The LSP shown in Fig. 12 is significantly smaller for the pessi mistic scenario than for the other two scenarios although the same amount of EVs is assumed. The upper limit is restricted to only
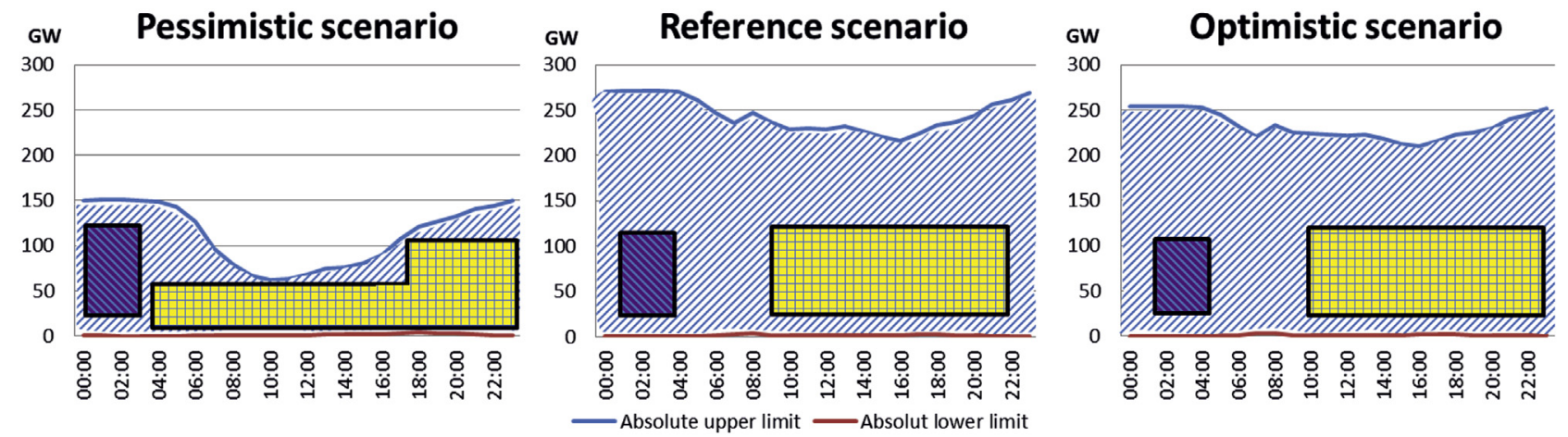

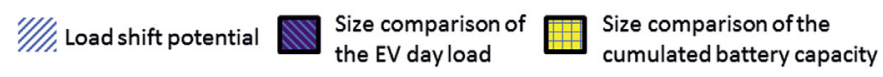

Fig. 12. LSP on a working day according to the scenarios. 
$150 \mathrm{GW}$ and since charging at work is not allowed, the upper limit drops significantly during day hours. $10 \%$ of the day load is bounded by the lower limit. For the pessimistic scenario, this results in a peak of $3.83 \mathrm{GW}$ at 6 p.m., in the reference scenario, the highest peak is with $3.55 \mathrm{GW}$ at $8 \mathrm{p} . \mathrm{m}$. in the morning. In the optimistic scenario, the peak occurs also at 8 p.m. with $3.43 \mathrm{GW}$. Considering the limits and the needed daily EV electricity demand, it becomes clear that a high LSP exists for all three scenarios. There would even be a LSP left, if the batteries of all cars were completely discharged at the beginning of the day and would have to be fully charged at the end of the day. This can be seen in Fig. 12: the yellow area (in the web version) which depicts the battery capacity fits easily below the upper limit.

\section{Exemplarily integration of the LSP in an energy system model}

Having calculated those limits to the LSP, it can be integrated into an energy system dispatch model as has been done in PERSEUS EMO [21]. PERSEUS EMO is a follow up model of PERSEUS EU [38]. The main difference to other PERSEUS model versions is the focus on the integration of the additional electricity demand caused by electric mobility. It is a dispatch and investment energy system model mapping the European energy system until 2030. It is a linear optimization model implemented in GAMS uti lizing the CPLEX solver and includes several million equations and variables. Based on a perfect foresight approach, the total dis counted system expenditures are minimized, whilst the demand for electricity and heat in each country is satisfied. The system expenditures in the objective function include several summands (ct. Equation (1)). The first summand contains the expenditures related to energy flows (FL). Those are mainly the fuel expenditures. Additionally there are system usage costs considered for some flows like transmission fees or financial incentives for electricity generation from renewable energies. Next, the variable costs of electricity generation are added. The third summand is composed of all the costs of the generation capacities. Those are the fixed costs for generation units as well as expenditures for the installation of new units. Furthermore, costs for load changes are included for thermal units such as coal, lignite and uranium fired power plants. The forth and the fifth summand consider the European emission trading system (EU ETS). Certificate trading costs are considered as well as possible penalties when emissions exceed the cap. Also, expenditures for certificates from flexible mechanisms of the Kyoto Protocol, like Clean Development Mechanism and Joint Imple mentation projects, are added if those are used.

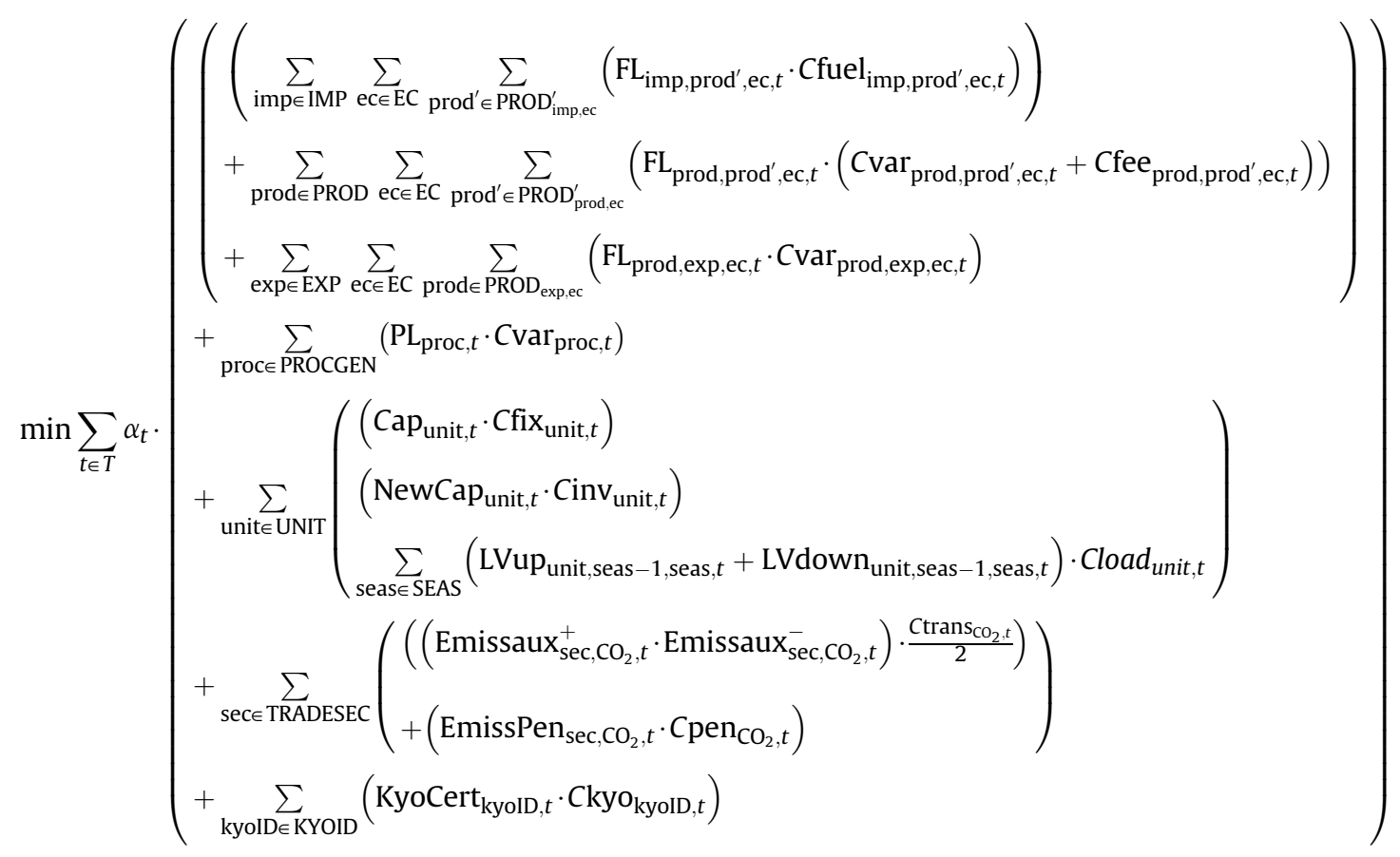

With:

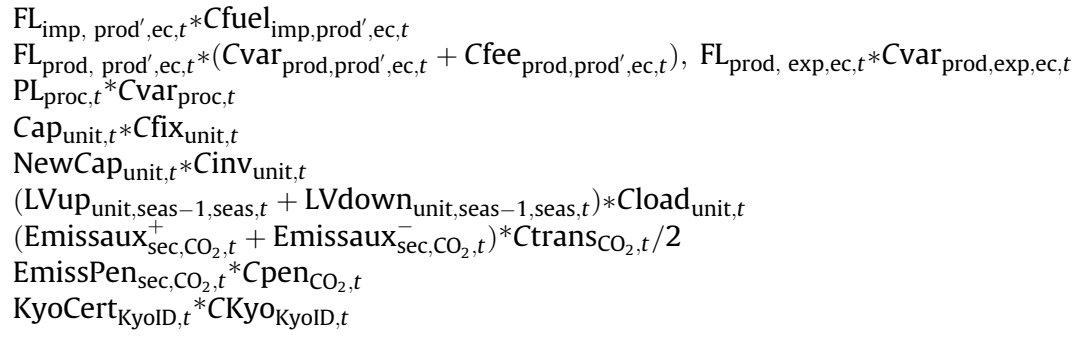

Fuel expenditures

Transmission fees

Variable costs of electricity generation

Fixed costs of generation units

Expenditures for new generation units Load changing costs

Certificate trading costs

Penalties for exceeding emissions

Costs for flexible mechanisms 
The objective function is complemented by further restrictions addressing technological, ecological and political frameworks which raise the complexity of the model. Each of the 22 repre sented European countries is mapped with its demand, its gener ation system [39], and its potential for installing new renewable and thermal capacities. The demand of each country has to be satisfied according to a load curve based on the ENTSO E [34] data. The operation of generation units is limited by minimal and maximal full load hours as well as by their availability and technical lifetime. Taking into account transmission losses, the countries can interchange electricity within the transmission capacity of the high voltage grid. With a base year of 2007 , at least every fifth year is calculated. The year itself is represented by three seasons: winter, summer, and a transition season. Each season is represented by a working day and a weekend day consisting of 21 time slots each. For each of the 126 time slots, energy and material flows are balanced in each of the 22 represented European countries. Besides that, the European emission trading system is integrated in the optimization in which certificate prices are calculated via marginal costs.

Additionally, the demand for electricity by EVs and the possi bility to shift their daily energy demand within the day has been integrated [21]. A first integration of the limits to the LSP of the EV day load shows that the lower limit is the restrictive constraint (cf. Fig. 13), even though it only bounds $10 \%$ of the day load. For the analysis in this paper, renewable energies are modeled as base load so that the LSP is only used to fill valleys in the demand and it is guaranteed that the installed units with low variable costs such as nuclear or lignite power plants increase their full load hours and avoid load variation costs.

It can be seen that the EVs are used for valley filling during night time. On a working day, over $70 \%$ of the EV day load is charged at night time until 7 a.m. in the morning and about another $20 \%$ at night time after 9 p.m. On the weekend, almost $95 \%$ of the day load is charged before 9 a.m. The charging is reduced to a minimum during the day and thus fills the morning valley in the conventional demand (cf. Fig. 6). The upper limit does not affect the results of the optimization so far. However, this could be different if due to renewable feed in negative balancing power is needed and the LSP is used to balance the volatile feed in. Even though the lower limit only bounds $10 \%$ of the EV day load, the charging curve is affected by it as on a working day about $5 \%$ of the day load is charged exactly according to the lower limit between 9 a.m. and 9 p.m.

\section{Conclusion and outlook}

In order to analyze the challenges that EVs might add to energy systems, the data about trips by car from different European mobility studies has been evaluated. Considering parameters such as the starting and the end time of different trips as well as the distances and destinations, charging curves have been generated for six European countries. The effects on the curves of a pessi mistic, a reference and an optimistic scenario of the EV develop ment have been evaluated to identify crucially influencing parameters. Comparing the national charging curves, some minor differences were identified. However, on the whole, the load curves of the additional electricity demand in the considered European member states look similar. Subsequently, the German mobility study has been used to illustrate differences in the charging behavior due to different residential areas within Germany. Dif ferences here are greatest between nucleated towns and largely rural areas. While assuming an uncontrolled charging in nucleated towns, the main load peak takes place in the morning, in largely rural areas it takes place in the evening. Through such analyses, the most important factors of influence on the curves could be iden tified to be the charging power and the possibility to charge at work. In the optimistic scenario, the high charging power leads to high peaks in the loading curve and thus might have a challenging impact on the local power grid. However, along with an optimistic development of the EV technology, the possibility of controlled charging of EVs is more likely. This could increase the load shifting potential by demand response considerably. Demand response at tempts to level the volatile load curve and leads therefore to an increase in full load hours of the thermal generating system and/or a direct consumption of the volatile generation by renewables. Looking at the possibility to integrate electricity from PV, the future importance of a controlled charging at work becomes obvious. For the case that both, PV cells and EVSEs, were allocated at the work places, the advantage of using decentralized energy without burdening the local grid would be given in addition. With a high penetration of EVs that could charge at work it could be possible to integrate a huge amount of PV electricity. Thus, employers should be supported in building up a charging infrastructure. Incentives to charge at work, e.g., low electricity rates, should be given to employees.

In order to analyze the benefits of LSP in more detail, upper and lower limits have been determined. Analyzing the mobility data, the upper limit was drafted according to the availability of EVs at EVSEs. It was found that in the pessimistic scenario in which charging is only allowed at home, in each country at least $24 \%$ of the vehicles are constantly available. In the reference scenario, where charging at work is also allowed, even $45 \%$ are constantly available. As a lower limit, we determined that $10 \%$ of the cumulated daily EV electricity demand has to be charged in an uncontrolled way. This has been done to consider drivers with a daily distance above the

\section{Working day, Germany}

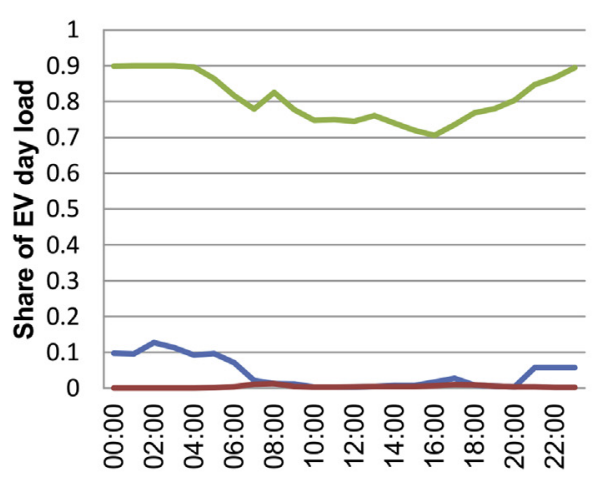

Weekend, Germany

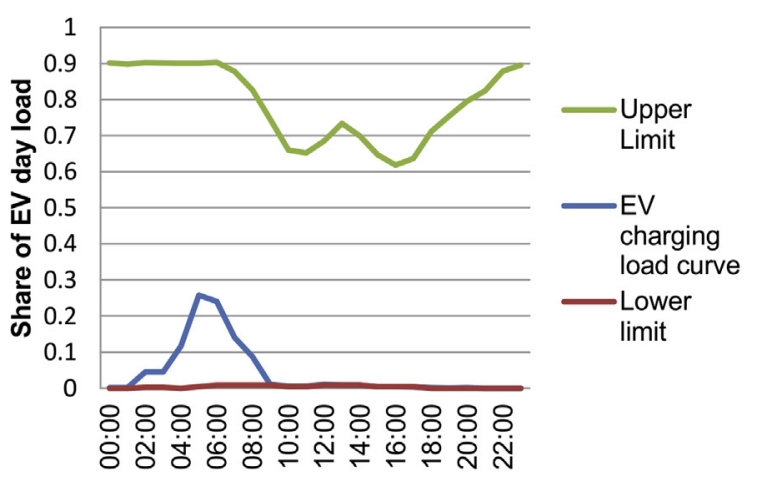

Fig. 13. Load dispatch in PERSEUS-EMO on a working day (left) and a weekend day (right). 
maximum reach of one battery filling as well as to have a safety margin for those who are not willing to take part in the controlled charging measure. At the current state of EV penetration, it is not possible to determine the share of people that are going to be willing to take part in those measures. With our assumptions of people always plugging in when possible and only $10 \%$ of uncon trolled charging, the LSP displayed tends to be overestimated. It shows, however, the overwhelming technical LSP of EVs with respect to their daily electricity demand.

As an example of application of the developed limits to the LSP, we have used them as an input in the energy system model PERSEUS EMO. The results show that the EVs are charged at times with a low conventional demand. Thereby, the remaining thermal generation units increase their annual full load hours and thus raise their efficiency and cost effectiveness. Because of the high avail ability of EVs at EVSEs at night time, the upper limit so far is not restrictive to the benefits of the LSP. The lower limit, however, turns out to be binding; even though only $10 \%$ of the day load is limited. To analyze the potential benefits of load shifting in more detail, we plan for future work to increase the time resolution of our analysis and integrate time dependent renewable in feed.

\section{References}

[1] IAE, EVI, International Energy Agency and Electric Vehicles Initiative of the Clean Energy Ministerial, Paris, France, 2013.

[2] C. Erdmenger, H. Lehmann, K. Müschen, J. Tambke, S. Mayr, K. Kuhnhenn, Energy Policy 37 (2009) 158 165. http://dx.doi.org/10.1016/j.enpol.2008.07. 031.

[3] P. Jochem, T. Kaschub, A.-G. Paetz, W. Fichtner, in: EVS26 International Battery, Hybrid and Fuel Cell Electric Vehicle Symposium, Los Angeles, 2012.

[4] O. Sundstrom, C. Binding, IEEE Trans. Smart Grid 3 (2012) 26 37. http://dx. doi.org/10.1109/tsg.2011.2168431.

[5] T. Pollok, E. Svczechowicz, C. Matrose, A. Schnettler, G. Stöckl, G. Kerber, M. Lödl, R. Witzmann, P. Behrens, in: VDE-Kongress, VDE, Leipzig, 2010.

[6] K. Clement-Nyns, E. Haesen, J. Driesen, IEEE Trans. Power Syst. 25 (2010) 371 380. http://dx.doi.org/10.1109/tpwrs.2009.2036481.

[7] W. Kempton, J. Tomić, J. Power Sources 144 (2005) 268 279. http://dx.doi. org/10.1016/j.jpowsour.2004.12.025.

[8] H. Lund, W. Kempton, Energy Policy 36 (2008) 3578 3587. http://dx.doi.org/ 10.1016/j.enpol.2008.06.007.

[9] C. Ahn, C.-T. Li, H. Peng, J. Power Sources 196 (2011) 10369 10379. http://dx. doi.org/10.1016/j.jpowsour.2011.06.093.

[10] L. Hillemacher, A. Eßer-Frey, W. Fichtner, Internationale Energiewirtschaftstagung, IEWT, Wien, 2011.

[11] T. Hahn, M. Schönfelder, P. Jochem, V. Heuveline, W. Fichtner, Smart Grid Renewable Energy 4 (2013) 398 408. http://dx.doi.org/10.4236/sgre.2013. 45046.
[12] F. Hacker, R. Harthan, F. Matthes, W. Zimmer, Environmental Impacts and Impact on the Electricity Market of a Large Scale Introduction of Electric Cars in Europe Critical Review of Literature, European Topic Centre on Air and Climate Change, Berlin, 2009.

[13] S. Bashash, S.J. Moura, J.C. Forman, H.K. Fathy, J. Power Sources 196 (2011) 541 549. http://dx.doi.org/10.1016/j.jpowsour.2010.07.001.

[14] X. Hu, S. Li, H. Peng, F. Sun, J. Power Sources 239 (2013) 449 457. http://dx. doi.org/10.1016/j.jpowsour.2013.03.157.

[15] A.G. Paetz, T. Kaschub, P. Jochem, W. Fichtner, in: 10th International Conference on the European Energy Market (EEM), 2013, 2013, pp. 17.

[16] R.A. Waraich, M.D. Galus, C. Dobler, M. Balmer, G. Andersson, K.W. Axhausen, Transp. Res. Part C Emerg. Technol. 28 (2013) 74 86. http://dx.doi.org/10. 1016/j.trc.2012.10.011.

[17] C.M. Flath, J.P. Ilg, S. Gottwalt, H. Schmeck, C. Weinhardt, Transportation Science, http://dx.doi.org/10.1287/trsc.2013.0467 (accepted in 2013).

[18] C. Fernandes, P. Frías, J.M. Latorre, Appl. Energy 96 (2012) 194 202. http://dx. doi.org/10.1016/j.apenergy.2011.11.058.

[19] C. Weiller, Energy Policy 39 (2011) 3766 3778. http://dx.doi.org/10.1016/j. enpol.2011.04.005

[20] D. Dallinger, D. Krampe, M. Wietschel, IEEE Trans. Smart Grid 2 (2011) 302 313.

[21] H. Heinrichs, Analyse der langfristigen Auswirkungen von Elektromobilität auf das deutschen Energiesystem im europäischen Energieverbund unter Berücksichtigung von Netzrestriktionen, dissertation, Karlsruhe Institute of Technology (KIT), Karlsruhe, 2013.

[22] M. Wietschel, E. Dütschke, S. Funke, A. Peters, P. Plötz, U. Schneider, A. Roser, J. Globisch, Fraunhofer ISI, IREES GmbH, Karlsruhe, 2012.

[23] A. Kihm, S. Trommer, M. Mehlin, in: Transportation Research Board, 92 Annual Meeting, Washington DC, 2013.

[24] S. Trommer, A. Kihm, P. Hebes, M. Merlin, European Transport Conference, Glasgow, Scotland, UK, 2010.

[25] C. Gringmuth, in: Karlsruher Beiträge zur Wirtschaftspolitischen Forschung, vol. 22, Nomos, Baden-Baden, 2007, $164 \mathrm{~S}$.

[26] K. Schmidt, P. Schäfer, Fachgruppe Verkehrsplanung und Öffentlicher Verkehr, Fachhochschule Frankfurt am Main, Frankfurt a. M., 2011, p. 258.

[27] ECOtality, Q4 2012 Report The EV Project, 2012.

[28] P.v.d. Bossche, O. Noshin, in: J.v. Mierlo (Ed.), Electric Vehicle Symposium EVS26, Los Angeles, 2012.

[29] BBSR, Siedlungsstrukturelle Kreistypen, Bundesinstitut für Bau, 2012.

[30] G. Stoeckl, R. Witzmann, J. Eckstein, in: Electrical Power and Energy Conference (EPEC), 2011 IEEE, 2011, pp. 415420.

[31] BMVBS, DLR, infas, in: DLR Institut für Verkehrsforschung, Berlin, 2008.

[32] N. Hartmann, E.D. Özdemir, J. Power Sources 196 (2011) 23112318 . http:// dx.doi.org/10.1016/j.jpowsour.2010.09.117.

[33] J.-H. Kim, A. Shcherbakova, Energy 36 (2011) 873 880. http://dx.doi.org/10. 1016/j.energy.2010.12.027.

[34] ENTSO-E, European Network of Transmission System Operators for Electricity, 2012.

[35] EEX, in: EEX-Transparenzplattform (Ed.), 2012.

[36] Bundesregierung, Energiekonzept 2050, 2011.

[37] T. Franke, I. Neumann, F. Bühler, P. Cocron, J.F. Krems, Appl. Psychol. 61 (2012) 368 391. http://dx.doi.org/10.1111/j.1464-0597.2011.00474.x.

[38] J. Rosen, The Future Role of Renewable Energy Sources in European Electricity Supply, dissertation, University of Karlsruhe, 2008.

[39] WEPP, in: U.P.G. Platts (Ed.), Washington, DC, 2009. 
Karlsruher Institut für Technologie

\section{Repository KITopen}

Dies ist ein Postprint/begutachtetes Manuskript.

Empfohlene Zitierung:

Babrowski, S.; Heinrichs, H.; Jochem, P.; Fichtner, W.

Load shift potential of electric vehicles in Europe.

2014. Journal of Power Sources, 255.

doi: $10.5445 / I R / 1000045134 /$ post

Zitierung der Originalveröffentlichung:

Babrowski, S.; Heinrichs, H.; Jochem, P.; Fichtner, W. Load shift potential of electric vehicles in Europe.

2014. Journal of Power Sources, 255, 283-293.

doi:10.1016/j.jpowsour.2014.01.019 